\title{
Comparison of the clinical outcomes of percutaneous vertebroplasty vs. kyphoplasty for the treatment of osteoporotic Kümmell's disease:a prospective cohort study
}

\author{
Jian-Zhong Chang ${ }^{1}$, Ming-Jian Bei ${ }^{2}$, Dong-Ping Shu' ${ }^{1}$, Cheng-Jun Sun ${ }^{1}$, Ji-Bin Chen ${ }^{3}$ and Ya-Ping Xiao ${ }^{1 *}$
}

\begin{abstract}
Background: Percutaneous vertebroplasty (PVP) and percutaneous kyphoplasty (PKP) are widely used in the treatment of Kümmell's disease. The purpose of this article is to investigate the clinical efficacy of PVP and PKP for Kümmell's disease.

Methods: The clinical data that 56 cases of Kümmell's disease treated with either PVP (28 cases) or PKP (28 cases) from December 2015 to December 2017 were prospectively analyzed. Gender, age, course of disease, injury segment, bone mineral density (BMD), visual analogue scale (VAS), Oswestry disability index (ODI), imaging measurement indexes before surgery between the two groups showed no significant difference (all $P>0.05$ ). The bone cement leakage rate, bone cement injection amount, operation time, VAS, ODI, the rate of vertebral compression, correction rate of kyphosis and refracture rate of adjacent vertebra in 2 years were compared between the two groups to calculate clinical efficacy.

Results: The two groups were followed up for 24-48 months. There was no significant difference in the follow-up time, amount of bone cement injected, incidence of bone cement leakage and refracture rate of adjacent vertebrae between the two groups (all $P>0.05$ ). The operation time, intraoperative blood loss and fluoroscopy times of the PVP group were significantly lower than those of the PKP group (all $P=0.000$ ). VAS score and ODI of the two groups were significantly lower at 1 day, 1 year and 2 years after surgery than before surgery (all $P<0.05$ ), but there was not statistically significant difference between the two groups at each time point after surgery (all $P>0.05$ ). The rate of vertebral compression and kyphosis correction in the two groups were significantly corrected $(P<0.05$, respectively) and decreased significantly with time (all $P<0.05$ ), But there was not significant difference between the two groups at any time point (all $P>0.05$ ).

(Continued on next page)
\end{abstract}

\footnotetext{
* Correspondence: xypine1314@163.com

'Department of Orthopedic Surgery, CR \& WISCO General Hospital, Wuhan University of Science and Technology, No. 209 Yejin Road, Wuhan 430000, Hubei Province, People's Republic of China

Full list of author information is available at the end of the article
}

(c) The Author(s). 2020 Open Access This article is licensed under a Creative Commons Attribution 4.0 International License, which permits use, sharing, adaptation, distribution and reproduction in any medium or format, as long as you give appropriate credit to the original author(s) and the source, provide a link to the Creative Commons licence, and indicate if changes were made. The images or other third party material in this article are included in the article's Creative Commons licence, unless indicated otherwise in a credit line to the material. If material is not included in the article's Creative Commons licence and your intended use is not permitted by statutory regulation or exceeds the permitted use, you will need to obtain permission directly from the copyright holder. To view a copy of this licence, visit http://creativecommons.org/licenses/by/4.0/. The Creative Commons Public Domain Dedication waiver (http://creativecommons.org/publicdomain/zero/1.0/) applies to the data made available in this article, unless otherwise stated in a credit line to the data. 
(Continued from previous page)

Conclusion: Both PVP and PKP can achieve similar effects in the treatment of Kümmell's disease. Because the cost, operation time, blood loss, radiation exposure and surgical procedure of PVP are less than those of PKP, PVP has more clinical priority value.

Keywords: Kümmell's disease, osteoporosis, Vertebral compression fracture, Percutaneous vertebroplasty, Percutaneous kyphoplasty

\section{Background}

Kümmell's disease is a special type of osteoporotic vertebral compression fracture (OVCF), which is relatively rare in clinical practice [1]. Kümmell's disease is also known as nonunion after OVCF, delayed vertebral osteonecrosis after trauma, and delayed vertebral collapse [2, 3]. Imaging examination can discover the late-onset collapse of vertebrae and characteristic change of intravertebral vacuum cleft (IVC), which is considered one of important inducing factors for injured vertebral progress after the collapse, deformity of kyphosis, intractable back pain and spinal cord damage after OVCF [4].

With the widespread development of percutaneous vertebroplasty (PVP) and percutaneous kyphoplasty (PKP) in the treatment of OVCF, many patients seek PVP or PKP treatment in order to restore the stability of the injured vertebrae and relieve low back pain $[5,6]$. Therefore, the literature on the use of PVP or PKP to treat Kümmell's disease has gradually increased, whose results showed that PKP and PVP can achieve good clinical results in treating this disease [7]. However, the selection criteria for PVP and PKP treatment are inconclusive at present.

Therefore, we conducted a comparative study on Kümmell's patients who received either PVP or PKP treatment in our hospitals from December 2015 to December 2017 to investigate the clinical efficacy, advantages and disadvantages of the two surgical methods, and to provide a reference for clinical selection of treatment methods.

\section{Methods}

\section{Selection criteria}

This study is a prospective, randomized, controlled study. The patients were blinded, but the researchers were not fully blinded. The inclusion criteria are as follows: (1) Patients suffered single-segment Kümmell's disease without new OVCF in the adjacent vertebrae; (2) Computed tomography (CT) or magnetic resonance imaging (MRI) examination confirmed the existence of IVC. the IVC refers to a significant radiolucency (gas containing), which is located centrally or adjacent to the vertebral body endplates as seen on CT or plain radiographs. On MRI, it is usually shown as a low signal intensity on a T1-weighted image and as a high signal or a low signal on a T2weighted image, depending on whether the fluid or gas fills the cleft [4]; (4) Dual energy X-ray measurement of bone mineral density (BMD) $\mathrm{T}$ value was less than -2.5 ; (5) PVP or PKP was conducted with bilateral pedicle; (6) Follow-up time was more than 2 years; (7) Postoperative calcium supplementation and anti-osteoporotic drugs were applied; (8) No fall or other trauma occurred. Exclusion criteria are as follows: (1) Patients with severe cardiopulmonary dysfunction; (2) Patients with coagulopathy; (3) Patients with local or systemic infection; (4) Patients with nerve root or spinal cord compression symptoms; (5) Patients with pathological fractures other than osteoporosis.

\section{Baseline data}

From December 2015 to December 2017, 56 of the 64 patients with Kümmell's disease met the selection criteria for inclusion in the study, of which 28 cases received PVP treatment (PVP group) and 28 cases received PKP treatment (PKP group) (Fig. 1). This study was approved by the ethics committees of authors' hospitals. All patients with clinical data and pictures gave written informed consent.

The PVP group included 6 males and 22 females, aged $63-85$ years, with an average of $75.0 \pm 5.8$ years. The course of disease was $2-14$ months, with an average of $8.7 \pm 3.0$ months. Twenty cases had no obvious history of trauma, and 8 cases had a history of falls. Injured

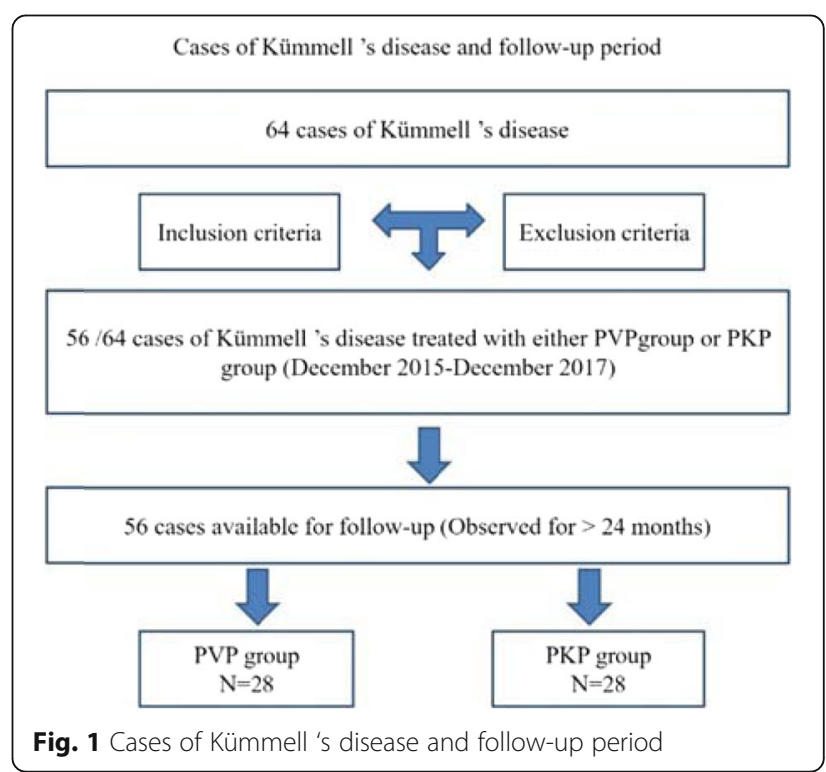


vertebra segments included 1 case in T9, 1 case in T10, 5 cases in T11, 8 cases in T12, 8 cases in L1, 2 cases in L2, 2 cases in L3, and 1 case in L4. The dual energy Xray $\mathrm{BMD} T$ value was $-2.83--6.13$, and the average value was $-4.35 \pm 0.91$.(Table 1 ).

The PKP group included 8 males and 20 females, aged $62-86$ years, with an average of $75.1 \pm 5.7$ years. The course of disease was 2-13 months, with an average of $8.4 \pm 2.9$ months. Eighteen cases had no obvious history of trauma, and 10 cases had history of falls. Injured vertebral segment included 2 cases of T9, 3 cases of T11, 7 cases of T12, 9 cases of L1, 4 cases of L2, and 1 case of L3 and 2 cases of L4. The dual energy X-ray BMD T value was $-2.54--5.91$, and the average value was $4.47 \pm 0.89$. (Table 1).

Gender, age, course of disease, injury segment, BMD, VAS, the Oswestry disability index (ODI) and imaging indexes of the two groups were comparable (all $P>0.05$, Tables 1, 2 and 3).

\section{Surgical procedures}

Both groups of surgeries were performed by the same group of physicians, and the PVP and PKP procedures followed the same principle (Fig. 2). The patients were placed in the prone position to maintain the spine's posterior extension for position reduction. Bilateral pedicle puncture with local anesthesia guided by $\mathrm{C}$-arm X-ray machine. PVP procedure: the working sleeve reached the IVC area in the anterior $1 / 3$ of the vertebra or close to the IVC area. Polymethylmethacrylate (Tecres SPA, Verona, Italy) was injected into the IVC region using a 3.5 $\mathrm{mm}$ side opening bone cement injector (Shanghai Kinetic Medical Co., Ltd., Shanghai, China) until the entire crack was fully filled and the cement was well dispersed. PKP procedure: after the working sleeve reached the IVC area, the extended balloon catheter (Shanghai Kinetic Medical Co., Ltd., Shanghai, China) was first delivered to the IVC area through the work channel. The balloon was expanded, and the pressure of the balloon

Table 1 Baseline data of the two groups

\begin{tabular}{lllll}
\hline Parameter & PVP group & PKP group & $\mathrm{t} / \mathrm{X}^{2}$ & $P$ \\
\hline Cases & 28 & 28 & & \\
Gender & & & & \\
$\quad$ Male (cases) & 6 & 8 & 0.381 & 0.537 \\
$\quad$ Female (cases) & 22 & 20 & & \\
Age (years) & $75.0 \pm 5.8$ & $75.1 \pm 5.7$ & -0.632 & 0.533 \\
Course of disease (months) & $8.7 \pm 3.0$ & $8.4 \pm 2.9$ & 0.960 & 0.338 \\
Fall history & & & & \\
$\quad$ Yes (cases) & 8 & 10 & 0.327 & 0.567 \\
$\quad$ No (cases) & 20 & 18 & & \\
BMD (T value) & $-4.35 \pm 0.91$ & $-4.47 \pm 0.89$ & -1.024 & 0.307 \\
\hline
\end{tabular}

system was controlled within $15 \mathrm{~atm}$ to make the satisfactory reduction of the fractures around the IVC area and the corresponding endplate. Finally, the bone cement was injected into the IVC region through the side opening injector until the entire fracture was filled.

\section{Postoperative management}

The patient remained in a supine position for $8-12 \mathrm{~h}$ after the operation. Patients were still confined to bed rest. Lumbar and back braces were used to protect the patient from bed during 1-2 months after the operation. Oral bisphosphonates, vitamin $\mathrm{D}$ and calcium tablets and other drugs were used for anti-osteoporosis treatment.

\section{Outcome measurement}

Clinical efficacy: the leakage rate of intraoperative bone cement, injection amount of bone cement, and operation time of the two groups were recorded. VAS score was used to evaluate the pain degree of low back [8]. The ODI was used to evaluate the severity of the dysfunction [9]. The incidence of new adjacent vertebral fracture was recorded in 2 years.

Imaging measurement indexes: the height of the injured vertebral body and the kyphosis angle were measured before and after the operation by the anteroposterior and lateral X-ray images [10]. And the following indexes were calculated. 1) Rate of vertebral compression = the height of the injured vertebral body / the average height of adjacent upper and lower vertebral body heights [10]; 2) Correction degree of kyphosis $=$ (preoperative kyphosis angle - postoperative kyphosis angle) / preoperative kyphosis angle $\times \%$ [11].

\section{Statistical analysis}

SPSS19.0 statistical software (IBM Corp., Armonk, NY, USA) was used for statistical analysis. Measurement data were expressed by mean \pm standard deviation. The Levene test was used to test the homogeneity of variance. The independent sample $t$ test and the One-Way ANOVA (Bonferroni or Dunnett T3) were used for inter-group comparisons at different time points. The repeated measures ANOVA was used for intra-group comparisons at different time points. The counting data were tested with $\chi^{2}$ test. Test level $\alpha$ was 0.05 .

\section{Results \\ Clinical outcomes}

The two groups were followed up for 24-48 months. The follow-up time and intraoperative amount of bone cement injection between the two groups was not significant difference $(P>0.05$, respectively). The operation time, intraoperative blood loss and fluoroscopy times of the PVP group were significantly lower than those of the PKP group (all $P=0.000$ ). Bone cement leakage occurred in 5 cases $(17.9 \%)$ of the PVP group, including 2 cases of 
Table 2 Comparison of clinical efficacy between the two groups

\begin{tabular}{|c|c|c|c|c|}
\hline Parameter & PVP group & PKP group & $t / x^{2}$ & $P$ \\
\hline Follow-up time (months) & $35.3 \pm 6.99$ & $35.2 \pm 7.63$ & 0.115 & 0.909 \\
\hline Amount of bone cement injected (ml) & $4.2 \pm 1.15$ & $4.6 \pm 1.55$ & -1.875 & 0.065 \\
\hline Operation time (min) & $34.8 \pm 3.47$ & $45.1 \pm 5.15$ & -56.032 & 0.000 \\
\hline Intraoperative blood loss (ml) & $16.9 \pm 3.49$ & $21.2 \pm 5.29$ & -15.479 & 0.000 \\
\hline Fluoroscopy times & $15.8 \pm 3.50$ & $20.5 \pm 4.16$ & -19.060 & 0.000 \\
\hline \multicolumn{5}{|l|}{ Bone cement leakage } \\
\hline Yes (cases) & 5 & 3 & 0.163 & 0.686 \\
\hline No (cases) & 24 & 25 & & \\
\hline \multicolumn{5}{|l|}{ VAS scores } \\
\hline Before surgery & $8.0 \pm 0.77$ & $8.0 \pm 0.75$ & 0.698 & 0.486 \\
\hline At 1 day after surgery & $2.8 \pm 0.75^{*}$ & $2.7 \pm 0.81^{*}$ & 0.301 & 0.764 \\
\hline At 1 year after surgery & $2.4 \pm 0.70^{*}$ & $2.6 \pm 0.84^{*}$ & -1.398 & 0.165 \\
\hline At 2 years after surgery & $2.5 \pm 0.70^{*}$ & $2.5 \pm 0.84^{*}$ & -0.356 & 0.722 \\
\hline \multicolumn{5}{|l|}{ ODI } \\
\hline Before surgery & $84.5 \pm 5.94$ & $84.9 \pm 8.23$ & -2.293 & 0.062 \\
\hline At 1 day after surgery & $29.0 \pm 7.62^{*}$ & $30.4 \pm 7.73^{*}$ & -3.533 & 0.056 \\
\hline At 1 year after surgery & $29.8 \pm 7.02^{*}$ & $29.9 \pm 7.01^{*}$ & -0.407 & 0.684 \\
\hline At 2 years after surgery & $29.9 \pm 7.11^{*}$ & $31.0 \pm 7.56^{*}$ & -2.872 & 0.054 \\
\hline \multicolumn{5}{|l|}{ Adjacent vertebral fractures } \\
\hline Yes (cases) & 2 & 3 & 0.220 & 0.639 \\
\hline No (cases) & 26 & 25 & & \\
\hline
\end{tabular}

${ }^{*}$ Compared to before surgery, $P=0.000$

anterior wall, 1 case of upper intervertebral space, 1 case of lower intervertebral space and 1 case of lateral wall. Bone cement leakage occurred in 3 cases $(10.7 \%)$ of the PKP group, including 1 case of anterior wall, 1 case of upper intervertebral space and 1 case of lateral wall. But no related clinical symptoms occurred in both groups. There was not significant difference in the number of incidence of bone cement leakage between the two groups $(P>0.05)$. (Table 2).

Table 3 Comparison of two groups of imaging data

\begin{tabular}{lllll}
\hline Parameter & PVP group & PKP group & $\mathrm{t} / \mathrm{X}^{2}$ & $P$ \\
\hline Rate of vertebral compression & & & & \\
Pre-operation & $0.74 \pm 0.11$ & $0.75 \pm 0.12$ & -0.088 & 0.930 \\
At 1 day after operation & $0.84 \pm 0.11^{*}$ & $0.86 \pm 0.09^{*}$ & -0.515 & 0.609 \\
At 1 year after operation & $0.82 \pm 0.13$ & $0.82 \pm 0.09$ & 0.248 & 0.805 \\
At 2 years after operation & $0.79 \pm 0.15$ & $0.80 \pm 0.11$ & -0.290 & 0.773 \\
Correction rate of kyphosis & & & & \\
At 1 day after operation & $31.0 \pm 6.34$ & $32.6 \pm 6.19$ & -2.467 & 0.053 \\
At 1 year after operation & $30.0 \pm 6.24 \#$ & $29.9 \pm 5.96 \#$ & 0.093 & 0.926 \\
At 2 years after operation & $28.8 \pm 6.37 \# \&$ & $28.7 \pm 6.59 \# \&$ & 0.509 & 0.611
\end{tabular}

* Compared to pre-operation, $P<0.05$

\# Compared with 1 day after operation, $P<0.05$

\& Compared with 1 year after operation, $P<0.05$
VAS score and ODI of the two groups were significantly lower at 1 days, 1 year and 2 years after surgery than before surgery (all $P<0.05$ ), and there was not statistical difference between the two groups at each time point after surgery (all $P>0.05$ ). During the 2 years of follow-up after the operation, 2 cases (7.1\%) of the PVP group and 3 cases $(10.7 \%)$ of the PKP group had adjacent vertebral fractures, and the difference between the two groups was not statistical difference $(P>0.05)$. (Table 2).

\section{Imaging evaluation outcomes}

The correction rate of kyphosis and rate of vertebral compression in the two groups were significantly corrected $(P<0.05$, respectively) and gradually decreased significantly with time (all $P<0.05$ ) (Tables 2 and 3 ), which indicates that the height of vertebral body and kyphosis angle were significantly recovered and gradually lost after surgery. These indexes between the two groups at any time point was not significant difference (all $P>$ 0.05, Table 3).

\section{Discussion}

We found that follow-up time, incidence of bone cement leakage, refracture rate of adjacent vertebra and 

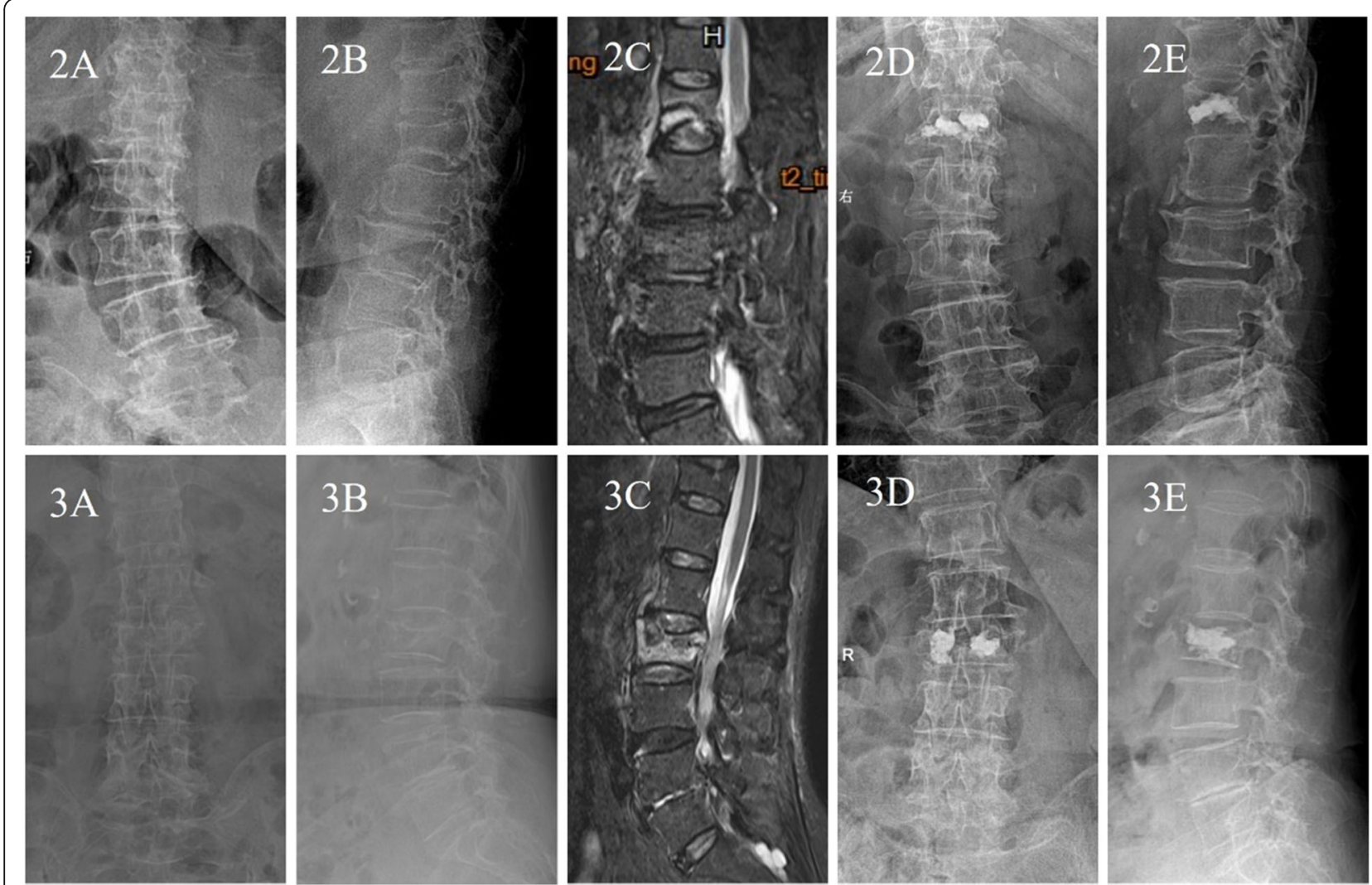

Fig. 2 A 75-year-old female patient with Kümmell's disease at L1 in PVP group:2A Anteroposterior X-ray film before operation; 2B Lateral X-ray film before operation; 2C MRI image before operation; 2D Anteroposterior X-ray film after operation; 2E Lateral X-ray film after operation. 3. A 83year-old female patient with Kümmell's disease at L2 in PKP group: 3A Anteroposterior X-ray film before operation; 3B Lateral X-ray film before operation; 3C MRI image before operation; 3D Anteroposterior X-ray film after operation; 3E Lateral X-ray film after operation

intraoperative amount of bone cement injection between the two groups was not statistical difference. Both groups significantly relieved patients' pain of low back, recovered the height of vertebral body and kyphosis angle and improved their quality of life, but PVP was associated with less surgical time, blood loss, and radiation exposure than those of PKP. The rate of vertebral compression and kyphosis correction between the two groups was not found significantly difference, but decreased significantly with time, which suggests that the correction was gradually lost.

Since 1984, Galiber et al. [12] applied PVP in the treatment of 1 case of $C 2$ vertebra invasive hemangioma to find its advantages of simple operation and definite effect. PVP and PKP have gradually become one of the effective methods to treat vertebral tumor and OVCF $[8,13,14]$. Kümmell's disease is a rare type in OVCF after minor trauma, which is progressive occurrence of vertebral collapse and kyphosis due to vertebral ischemia and necrosis. Kümmell's disease is often manifested as intractable pain of low back, pseudojoint formation, and may be accompanied by nerve injury in severe cases $[15,16]$. In plain radiographs and CT imaging of vertebral body pseudoarthrosis, the fracture sites often present gas accumulation, which is termed the vacuum phenomenon or IVC sign. Vacuum phenomena often appear as intravertebral radiolucent shadows that are typically band like or linear in shape and are often accompanied by peripheral sclerosis [17]. MRI imaging can find limited fluid filling in the vertebral body. So Kümmell's disease is also referred to as delayed posttraumatic vertebral collapse disease, nonunion of vertebral fractures, and vertebral ischemic necrosis $[1,2,18]$. Previous studies have suggested that IVC is mainly located in the thoracolumbar region $[4,19]$, which is similar to the segmental distribution of the two groups of patients in this study. $87.5 \%$ of the fractured vertebral bodies were located in the thoracolumbar segment, most of which were wedge fractures. And the fissures mostly occurred near the upper or lower endplate of the vertebral body. These suggests that the occurrence of the disease may be related to the repeated stress activity and high mobility in the thoracolumbar segment, leading to vertebral nonunion and ischemic necrosis.

Previous studies have found that a small dose of bone cement can restore the mechanical properties of the fractured vertebral body, and the injection amount of 
bone cement has no significant correlation with the analgesic effect, even believed that $1.5 \mathrm{ml}$ of bone cement is injected into each vertebral body to obtain satisfactory analgesic effect [20, 21]. Biomechanics studies in vitro have confirmed that the strength of the vertebral body can be restored by injecting about $2 \mathrm{ml}$ bone cement or $16 \%$ of the vertebral volume with bone cement, and the stiffness of the vertebral body can be restored by injecting about $4 \mathrm{ml}$ bone cement or $24 \%$ of the vertebral volume with bone cement [21]. In this study, the average injection amount of bone cement was $4.2 \pm 1.15 \mathrm{ml}$ in the PVP group and $4.6 \pm 1.55 \mathrm{ml}$ in the PKP group, both of which met the requirements of restoring the strength and stiffness of the vertebral body without significant difference between the two groups.

Significant pain relief was observed after surgery in both groups, and maintained until the last follow-up, However, no significant difference was seen between the groups. After filling the fissures in the vertebral body with bone cement, the height and kyphosis deformity of the vertebral body were partially restored and corrected, and the abnormal activity of the injuried vertebral body was eliminated, which was an important reason for pain relief [11]. Previous studies have found that both PVP and PKP can effectively relieve the lower back pain of Kümmell's disease, achieve satisfactory clinical effect, and partially restore the height of the vertebra and correct the kyphosis [11, 22-29]. During spinal flexion and extension, due to the presence of IVC and the formation of pseudojoint, the injured vertebra of Kümmell's disease can stretch and expand, which can widen the fractured vertebral body. Therefore, the height of the collapsed vertebral body can be retracted and kyphosis has been partially corrected during spinal hyperextension. In PVP treatment, bone cement is usually limited to diffusion in the fissure, which can maintain the effect of hyperextension kyphotic correction without the help of balloon dilation for reduction in PKP treatment. Previous studies have also found that patients with Kümmell's disease can achieve spontaneous reduction in the postextensor position without further balloon expansion reduction [30, 31]. Heo et al. [32] reported that excessive reduction tends to accelerate the process of vertebral ischemia and necrosis, leading to severe re-collapse. Therefore, excessive reduction of intraoperative injured vertebra should be avoided. We found that the rates of vertebral compression and kyphosis correction both in PVP and PKP groups obtained obvious correction, but no statistical difference of the rates between the two groups was observed, which further confirmed the point of view " patients of Kümmell 's disease can have spontaneous reduction in the posterior extension without further balloon expansion ".

We found that the rates of vertebral compression and kyphosis correction in the two groups gradually decreased significantly with time, suggesting that vertebral height and kyphosis angle gradually lost after surgery, which was consistent with previous findings $[7,14]$. In the treatment of OVCF without IVC by PVP and PKP, the injected bone cement of the former is mainly embedded in cancellous bone, while the bone cement of the latter is mainly filled with clumps, so stress occlusion is more likely to occur after PKP and lead to recollapse [33]. However, in this study, there was no significant difference of the vertebral recollapse between the two groups after 2 years of postoperation. The reason was that the distribution of bone cement in the IVC region was inconsistent with that in the non-IVC region. Due to the low pressure in the IVC region and the obstruction of the surrounding fibrous membrane, IVC was used as a "reservoir" during intraoperative injection of bone cement in both groups, and bone cement was filled in the IVC region in the form of solid masses. The limited bone cement mass cannot connect with the adjacent endplates of the upper and lower levels and strengthen cancellous bone of the vertebrae, thus failing to support the normal physiological stress from the body and causing the collapse again [34].

The most common complications of PVP and PKP are bone cement leakage and adjacent vertebral fractures $[35,36]$. The incidences of cement leakage of PVP and PKP for OVCF were 54.7 and $18.4 \%$, respectively [36]. Krauss et al. [37] reported that in the treatment of OVCF with IVC by PVP, the bone cement leakage rate was $18.2 \%$. Wang et al. [38] reported that the bone cement leakage rate of OVCF with IVC was $7.4 \%$ in PKP treatment. This study found that the leakage rates of bone cement were 17.9 and $10.7 \%$ in PVP and PKP group respectively, and both are similar to previous studies, which may be related to accurate preoperatively measurement of surgical approach, careful operation by the operator and not pursuing the maximum amount of bone cement. Besides, kümmell's disease exists obvious hardened zone and "crack" of vertebral body. A closed space is formed by the fissure, the surfaces of hardened zone, and the anterior longitudinal ligament. The injection of bone cement is confined in the closed space, and less prone to spread to other parts of the vertebral body. Therefore, the abnormal leakage of bone cement both in PKP group and PVP group was lower than that in the treatment of OVCF. In this study, although there was no significant difference of the bone cement leakage rate between the PVP group and the PKP group, the bone cement leakage rate of the PKP group was lower than that of the PVP group. The reason was mainly related to the fact that the PKP group could squeeze the surrounding cancellous bone during balloon expansion and reduce the bone cement leakage. In the other study, among the 219 patients of OVCF with single thoracolumbar fractures, 29 cases (13.2\%) occurred non-surgical 
vertebral fractures in the PKP treatment [39]. Eleven patients (14.1\%) in the early PVP group $(n=78)$ and 18 patients (39.1\%) in the late PVP group $(n=46)$ experienced an adjacent vertebral fractures during the first year following PVP [40]. In this study, the secondary fracture rates of PVP and PKP were 7.1 and 10.7\%, respectively, which were both lower than previous studies, and may be related to postoperative restriction of premature activity, thoracolumbar protection and continuous anti-osteoporosis treatment.

However, this study also had the following limitations. Despite the use of the blinded and random fashion, researchers failed to fully implement the principle of blindness. This was a prospective study with a small number of patients in each group. Furthermore, there is a lack of time biomechanical study on cement distribution in vertebrae to support the results. The current findings require further validation in multicenter, randomized, double-blind clinical trials.

\section{Conclusion}

Both PVP and PKP can achieve similar effects in the treatment of Kümmell's disease with the advantages of simple operation, short operation time, small trauma, and quick recovery, which can restore the partial height and kyphosis of the fractured vertebral body, quickly alleviate pain and improve the living quality of patients. Because the cost, operation time, blood loss, radiation exposure and surgical procedure of PVP are less than those of PKP, PVP has more clinical priority value.

\section{Abbreviations \\ PVP: Percutaneous vertebroplasty; PKP: Percutaneous kyphoplasty; OVCF: Osteoporotic vertebral compression fracture; IVC: Intravertebral vacuum cleft; ODI: Oswestry disability index; VAS: Visual analogue scale}

\section{Acknowledgements}

Ya-Ping Xiao would like to thank Cong-Hui Qian for English language editing as well as silent support for life and work.

\section{Authors' contributions}

All authors made substantive intellectual contributions in this study to qualify as authors. X YP and C JZ designed this study. MJ B, DP S, CJ S and C $J B$ participated in collecting and analyzing raw materials. An initial draft of the manuscript was written by X YP and C JZ. MJ B, DP S, CJ S and X YP redrafted parts of the manuscript and provided helpful advice on the final revision. All authors were involved in writing the manuscript. All authors read and approved the final manuscript.

\section{Funding}

MJ B and YP X receive research support from the National Natural Science Foundation of China (Grant No: 31671235) for the collection, analysis, and interpretation of data.

\section{Availability of data and materials}

The datasets used and/or analysed during the current study are available from the corresponding author on reasonable request.

\section{Ethics approval and consent to participate}

This study were approved by the institutional review boards/Ethics Committees of CR \& WISCO General Hospital, and was conducted in compliance with the ethical principles of the Helsinki Declaration of 1975.
Written informed consent was obtained from the patients or their family members.

\section{Consent for publication}

Not Applicable.

\section{Competing interests}

No potential conflict of interest relevant to this article was reported.

\section{Author details}

${ }^{1}$ Department of Orthopedic Surgery, CR \& WISCO General Hospital, Wuhan University of Science and Technology, No. 209 Yejin Road, Wuhan 430000, Hubei Province, People's Republic of China. ${ }^{2}$ Department of Orthopedic Surgery, Emergency General Hospital, Beijing 100028, People's Republic of China. ${ }^{3}$ Department of Orthopedics, Wuhan Hanyang Hospital, Wuhan University of Science and Technology, Wuhan 430050, People's Republic of China.

Received: 18 February 2020 Accepted: 7 April 2020

Published online: 13 April 2020

\section{References}

1. Lim J, Choi S-W, Youm J-Y, Kwon H-J, Kim S-H, Koh H-S. Posttraumatic delayed vertebral collapse : Kummell's disease. J Korean Neurosurg Soc. 2018;61(1):1-9.

2. D'Oria S, Delvecchio C, Dibenedetto M, Zizza F, Somma C. Case report of Kummell's disease with delayed onset myelopathy and the literature review. Eur J Orthop Surg Traumatol. 2018;28(2):309-16.

3. Young WF, Brown D, Kendler A, Clements D. Delayed post-traumatic osteonecrosis of a vertebral body (Kummell's disease). Acta Orthop Belg. 2002;68(1):13-9.

4. Yu W, Liang D, Yao Z, Qiu T, Ye L, Jiang X. The therapeutic effect of intravertebral vacuum cleft with osteoporotic vertebral compression fractures: a systematic review and meta-analysis. Int J Surg. 2017;40:17-23.

5. Zuo X-H, Zhu X-P, Bao H-G, Xu C-J, Chen H, Gao X-Z, Zhang Q-X. Network meta-analysis of percutaneous vertebroplasty, percutaneous kyphoplasty, nerve block, and conservative treatment for nonsurgery options of acute/ subacute and chronic osteoporotic vertebral compression fractures (OVCFs) in short-term and long-term effects. Medicine. 2018;97(29):e11544.

6. Zhang H, Xu C, Zhang T, Gao Z, Zhang T. Does percutaneous Vertebroplasty or balloon Kyphoplasty for osteoporotic vertebral compression fractures increase the incidence of new vertebral fractures? A meta-analysis. Pain Physician. 2017;20(1):E13-28

7. Patel A, Carter KR. Percutaneous Vertebroplasty and Kyphoplasty. In: StatPearls. Treasure Island (FL): StatPearls Publishing; 2020.

8. Khan M, Kushchayev SV. Percutaneous vertebral body augmentations: the state of art. Neuroimaging Clin N Am. 2019;29(4):495-513.

9. Zhang Y, Shi L, Tang P, Zhang L. Comparison of the efficacy between two micro-operative therapies of old patients with osteoporotic vertebral compression fracture: a network meta-analysis. J Cell Biochem. 2017;118(10): 3205-12.

10. Chen C, Fan P, Xie X, Wang Y. Risk Factors for Cement Leakage and Adjacent Vertebral Fractures in Kyphoplasty for Osteoporotic Vertebral Fractures. Clin Spine Surg. 2020. https://doi.org/10.1097/BSD. 0000000000000928

11. Jiang J, Gu F-L, Li Z-W, Zhou Y. The clinical efficacy and experience of bipedicular percutaneous vertebroplasty combined with postural reduction in the treatment of Kümmell's disease. BMC Musculoskelet Disord. 2020; 21(1):82.

12. Galibert $P$, Deramond $H$, Rosat $P$, Le Gars D. Preliminary note on the treatment of vertebral angioma by percutaneous acrylic vertebroplasty. Neurochirurgie. 1987;33(2):166-8.

13. Dydyk AM, M Das J. Vertebral augmentation. In: StatPearls. Treasure Island (FL): StatPearls Publishing; 2020.

14. Huang S, Zhu X, Xiao D, Zhuang J, Liang G, Liang C, Zheng X, Ke Y, Chang $Y$. Therapeutic effect of percutaneous kyphoplasty combined with antiosteoporosis drug on postmenopausal women with osteoporotic vertebral compression fracture and analysis of postoperative bone cement leakage risk factors: a retrospective cohort study. J Orthop Surg Res. 2019;14(1):452. 
15. Liu F, Chen Z, Lou C, Yu W, Zheng L, He D, Zhu K. Anterior reconstruction versus posterior osteotomy in treating Kümmell's disease with neurological deficits: a systematic review. Acta Orthop Traumatol Turc. 2018;52(4):283-8.

16. Huang Y-S, Hao D-J, Wang X-D, Sun H-H, Du J-P, Yang J-S, Gao J, Xue P. Long-segment or bone cement-augmented short-segment fixation for Kummell disease with neurologic deficits? A comparative cohort study. World Neurosurg. 2018;116:e1079-86.

17. Feng S-W, Chang M-C, Wu H-T, Yu J-K, Wang S-T, Liu C-L. Are intravertebral vacuum phenomena benign lesions? Eur Spine J. 2011;20(8):1341-8.

18. He D, Yu W, Chen Z, Li L, Zhu K, Fan S. Pathogenesis of the intravertebral vacuum of Kümmell's disease. Exp Ther Med. 2016;12(2):879-82.

19. Kim H, Jun S, Park SK, Kim G-T, Park SH. Intravertebral vacuum cleft sign: a cause of vertebral cold defect on bone scan. Skelet Radiol. 2016;45(5):707-12.

20. Molloy S, Mathis JM, Belkoff SM. The effect of vertebral body percentage fill on mechanical behavior during percutaneous vertebroplasty. Spine. 2003; 28(14):1549-54.

21. Graham J, Ahn C, Hai N, Buch BD. Effect of bone density on vertebral strength and stiffness after percutaneous vertebroplasty. Spine. 2007;32(18): E505-11.

22. Huang Y, Peng M, He S, Tang X, Dai M, Tang C. Clinical efficacy of percutaneous Kyphoplasty at the hyperextension position for the treatment of osteoporotic Kümmell disease. Clin Spine Surg. 2016;29(4):161-6.

23. Kim P, Kim SW. Balloon Kyphoplasty: an effective treatment for Kummell disease? Korean J Spine. 2016;13(3):102-6.

24. Li H-K, Hao D-J, Yang J-S, Huang D-G, Yu C-C, Zhang J-N, Gao L, Li H, Qian B. Percutaneous kyphoplasty versus posterior spinal fixation with vertebroplasty for treatment of Kümmell disease: a case-control study with minimal 2-year follow-up. Medicine. 2017;96(51):e9287.

25. Park JW, Park J-H, Jeon HJ, Lee JY, Cho BM, Park S-H. Kümmell's disease treated with percutaneous Vertebroplasty: minimum 1 year follow-up. Korean J Neurotrauma. 2017;13(2):119-23.

26. Sun $Y$, Xiong $X$, Wan D, Deng $X$, Shi H, Song S, Wu X, Zhou J, Yang M. Effectiveness comparison between unilateral and bilateral percutaneous kyphoplasty for Kümmell disease. Zhongguo xiu fu chong jian wai ke za zhi = Zhongguo xiufu chongjian waike zazhi $=$. Zhongguo Xiu Fu Chong Jian Wai Ke Za Zhi. 2017:31(9):1086-91.

27. Xia Y-H, Chen F, Zhang L, Li G, Tang Z-Y, Feng B, Xu K. Percutaneous kyphoplasty treatment evaluation for patients with Kümmell disease based on a two-year follow-up. Exp Ther Med. 2018;16(4):3617-22.

28. Zhang J, Fan $Y$, He X, Meng Y, Huang Y, Jia S, Du J, Wu Q, Hao D. Is percutaneous kyphoplasty the better choice for minimally invasive treatment of neurologically intact osteoporotic Kümmell's disease? A comparison of two minimally invasive procedures. Int Orthop. 2018;42(6): 1321-6.

29. Xiong X-M, Sun Y-L, Song S-M, Yang M-Y, Zhou J, Wan D, Deng X-G, Shi HG. Efficacy of unilateral transverse process-pedicle and bilateral puncture techniques in percutaneous kyphoplasty for Kummell disease. Exp Ther Med. 2019;18(5):3615-21

30. Hur W, Choi SS, Lee M, Lee DK, Lee JJ, Kim K. Spontaneous vertebral reduction during the procedure of Kyphoplasty in a patient with Kummell's disease. Korean J Pain. 2011;24(4):231-4.

31. Hur W, Lee JJ, Kim J, Kang SW, Lee IO, Lee MK, Choi SS. Spontaneous air reduction of vertebra plana with Kummell's disease during vertebroplasty: subsequent experience with an intentional trial. Pain Med. 2014;15(7):1240-2

32. Heo DH, Chin DK, Yoon YS, Kuh SU. Recollapse of previous vertebral compression fracture after percutaneous vertebroplasty. Osteoporos Int. 2009;20(3):473-80.

33. Niu J, Zhou H, Meng Q, Shi J, Meng B, Yang H. Factors affecting recompression of augmented vertebrae after successful percutaneous balloon kyphoplasty: a retrospective analysis. Acta Radiol. 2015;56(11):1380-7.

34. Kim Y-Y, Rhyu K-W. Recompression of vertebral body after balloon kyphoplasty for osteoporotic vertebral compression fracture. Eur Spine J. 2010;19(11):1907-12.

35. Chen W, Xie W, Xiao Z, Chen H, Jin D, Ding J. Incidence of cement leakage between unilateral and bilateral percutaneous vertebral augmentation for osteoporotic vertebral compression fractures: a meta-analysis of randomized controlled trials. World Neurosurg. 2019:122:342-8.

36. Zhan Y, Jiang J, Liao H, Tan H, Yang K. Risk factors for cement leakage after Vertebroplasty or Kyphoplasty: a meta-analysis of published evidence. World Neurosurg. 2017;101:633-42.
37. Krauss M, Hirschfelder H, Tomandl B, Lichti G, Bär I. Kyphosis reduction and the rate of cement leaks after vertebroplasty of intravertebral clefts. Eur Radiol. 2006;16(5):1015-21.

38. Wang G, Yang $\mathrm{H}$, Chen $\mathrm{K}$. Osteoporotic vertebral compression fractures with an intravertebral cleft treated by percutaneous balloon kyphoplasty. J Bone Joint Surg (Br). 2010;92(11):1553-7.

39. Wu J, Guan Y-H, Fan S-L. Risk factors of non-surgical vertebral fracture after percutaneous kyphoplasty of single segment thoracolumbar fracture. Zhongguo Gu Shang. 2017;30(9):833-7.

40. Yang C-C, Chien J-T, Tsai T-Y, Yeh K-T, Lee R-P, Wu W-T. Earlier Vertebroplasty for osteoporotic thoracolumbar compression fracture may minimize the subsequent development of adjacent fractures: a retrospective study. Pain Physician. 2018;21(5):E483-91.

\section{Publisher's Note}

Springer Nature remains neutral with regard to jurisdictional claims in published maps and institutional affiliations.

\section{Ready to submit your research? Choose BMC and benefit from:}

- fast, convenient online submission

- thorough peer review by experienced researchers in your field

- rapid publication on acceptance

- support for research data, including large and complex data types

- gold Open Access which fosters wider collaboration and increased citations

- maximum visibility for your research: over $100 \mathrm{M}$ website views per year

At $\mathrm{BMC}$, research is always in progress.

Learn more biomedcentral.com/submissions 